\title{
Proposta de um indicador de salubridade ambiental (ISA) para análise do saneamento no campus da Universidade Federal de Sergipe-São Cristóvão, Brasil
}

\author{
Proposal for an environmental health indicator (ISA) for sanitation analysis on the Federal \\ University of Sergipe campus-São Cristóvão, Brazil
}

Propuesta de indicador de salud ambiental (ISA) para análisis de saneamiento en el campus de la Universidad Federal de Sergipe-São Cristóvão, Brasil

\section{Resumo}

No Brasil, há uma grande deficiência quando se trata de abastecimento de água potável, coleta e tratamento de esgoto, coleta e destinação correta de resíduos sólidos, além de melhor gerenciamento dos recursos hídricos e cuidado com a saúde pública nos centros urbanos. Existem diversas leis, portarias e resoluções que determinam como estes serviços devem ser oferecidos às pessoas, porém, mais da metade da população brasileira não tem esses direitos assegurados, encontrando-se em situações insalubres. Por conta disso, o Conselho Estadual de Saneamento no Estado de São Paulo (CONESAN), em 1999, criou um modelo que permitiu às autoridades locais avaliarem a salubridade ambiental de uma determinada região. Assim, o presente estudo teve como objetivo a avaliação, a partir da adaptação da metodologia do CONESAN, da condição de salubridade da cidade Universitária Prof. José Aloísio de Campos, localizada em São Cristóvão/SE. A adaptação se fez necessária em função das especificidades locais e devido ao foco da pesquisa estar baseada fortemente no saneamento básico do campus. O indicador de salubridade ambiental para este estudo foi denominando de ISA-UFS, o qual considerou como subindicadores específicos: Abastecimento de Água, Resíduos Sólidos, Esgotamento Sanitário, Drenagem Urbana e Controle de Vetores. A partir dos resultados obtidos, foi possível interpretar a situação atual do saneamento do campus para uma condição de Média Salubridade (ISA-UFS $=0,66$ ), com potencial de melhora após realização de simples alterações nos serviços de saneamento, como limpeza diária das vias externas e aumento da frequência de coleta dos resíduos sólidos.

Palavras-chave: Saneamento básico; Indicador de salubridade ambiental; Impactos ambientais.

\begin{abstract}
In Brazil, there is a great deficiency when it comes to drinking water supply, sewage collection and treatment, collection and correct disposal of solid waste, as well as better management of water resources and care for public health in urban centers. There are several laws, ordinances and resolutions that determine how these services should be offered to people, however, more than half of the Brazilian population does not have these rights ensured, finding themselves in unhealthy situations. Because of this, the State Sanitation Council in the State of São Paulo (CONESAN), in 1999, created a model that allowed local authorities to assess the environmental health of a given region. Thus, the present study aimed to assess, based on the adaptation of the CONESAN methodology, the health condition of the University city Prof. José Aloísio de Campos, located in São Cristóvão SE. Adaptation was necessary due to local specificities and due to the focus of the research being strongly based on basic sanitation on campus. The
\end{abstract}


environmental health indicator for this study was called ISA-UFS, which considered as specific sub-indicators: Water Supply, Solid Waste, Sanitary Sewage, Urban Drainage and Vector Control. From the results obtained, it was possible to interpret the current sanitation situation of the campus to a condition of Medium Health (ISA-UFS $=0.66$ ), with potential for improvement after making simple changes in sanitation services such as daily cleaning of roads and increased frequency of solid waste collection.

Keywords: Basic sanitation; Environmental health indicator; Environmental impacts.

\section{Resumen}

En Brasil, hay una gran deficiencia en lo que respecta al suministro de agua potable, recogida y tratamiento de aguas residuales, recogida y correcta disposición de residuos sólidos, así como una mejor gestión de los recursos hídricos y cuidado de la salud pública en los centros urbanos. Existen varias leyes, ordenanzas y resoluciones que determinan cómo se deben ofrecer estos servicios a las personas, sin embargo, más de la mitad de la población brasileña no tiene estos derechos asegurados, encontrándose en situaciones insalubres. Por cuenta de eso, el Consejo Estatal de Saneamiento del Estado de São Paulo (CONESAN), en 1999, creó un modelo que permitió a las autoridades locales evaluar la salud ambiental de una determinada región. Así, el presente estudio tuvo como objetivo evaluar, a partir de la adaptación de la metodología CONESAN, el estado de salud de la ciudad universitaria Prof. José Aloísio de Campos, ubicado en São Cristóvão/SE. La adaptación fue necesaria debido a las especificidades locales y debido a que el enfoque de la investigación se basa fuertemente en el saneamiento básico en el campus. El indicador de salud ambiental para este estudio fue denominado ISA-UFS, el cual consideró como subindicadores específicos: Abastecimiento de Agua, Residuos Sólidos, Alcantarillado Sanitario, Drenaje Urbano y Control de Vectores. A partir de los resultados obtenidos, fue posible interpretar la situación actual de saneamiento del campus a una condición de Salud Media (ISA-UFS =0,66), con potencial de mejora después de realizar simples cambios en los servicios de saneamiento, como la limpieza diaria de los caminos públicos y mayor frecuencia del recogido de residuos sólidos.

Palabras clave: Saneamiento básico; Indicador de salud ambiental; Impactos ambientales.

\section{Introdução}

Os serviços de saneamento ambiental são muito importantes para o desenvolvimento de um país, pois melhora a qualidade de vida urbana além de preservar o meio ambiente, por outro lado, a falta de saneamento impacta diretamente no desempenho do trabalho, da educação, na saúde e no turismo do país. No Brasil, ainda há muito que melhorar, pois cerca de 35 milhões de brasileiros ainda não têm acesso à água tratada e aproximadamente 100 milhões de brasileiros não têm acesso à coleta de esgoto, ou seja, é necessária uma ampliação e reforço das leis, com o objetivo de proporcionar os serviços de saneamento para toda a população (Oliveira, Scazufca \& Pires, 2020).

Para identificar e avaliar os serviços básicos de saneamento é comum utilizar métodos que auxiliam com as práticas de desenvolvimento sustentável. Neste sentido, o Indicador de Salubridade Ambiental (ISA) foi elaborado pela Câmara Técnica de Planejamento do Conselho Estadual de Saneamento no Estado de São Paulo (CONESAN) com o objetivo de atender as normas e regulamentos da Política Estadual de Saneamento do Estado de São Paulo de forma a avaliar a eficácia do Plano Estadual de Saneamento. Originalmente, o ISA foi elaborado para contar com seis subindicadores os quais não estão apenas relacionados como saneamento ambiental, sendo também relacionados com a saúde pública, a situação socioeconômica e os recursos hídricos (Subindicador de Abastecimento de Água $\left(\mathrm{I}_{\mathrm{AB}}\right)$; Subindicador de Esgoto Sanitário ( $\mathrm{I}_{\mathrm{ES}}$ ); Subindicador de Resíduos Sólidos $\left(\mathrm{I}_{\mathrm{RS}}\right)$; Subindicador de Controle de Vetores $\left(\mathrm{I}_{\mathrm{CV}}\right)$; Subindicador de Riscos de Recursos Hídricos $\left(\mathrm{I}_{\mathrm{RH}}\right)$ e Subindicador Socioeconômico (ISE)) (Conesan, 1999).

Segundo a Lei Estadual de São Paulo $n^{\circ} 7.750 / 1992$ o ISA é calculado utilizando uma média ponderada de subindicadores específicos e associados, direta ou indiretamente, com a salubridade ambiental, Equação (1).

$$
I S A=0,25 I_{A B}+0,25 I_{E S}+0,25 I_{R S}+0,10 I_{C V}+0,10 I_{R H}+0,05 I_{S E}
$$


Research, Society and Development, v. 10, n. 1, e9110111515, 2021

(CC BY 4.0) | ISSN 2525-3409 | DOI: http://dx.doi.org/10.33448/rsd-v10i1.11515

Sua pontuação segue uma escala de 0 (zero) a 1,0 (um), em que 1,0 ponto significa a ausência virtual do risco a vida e 0 um risco extremo de vida (Almeida, 1999). O CONESAN elaborou uma faixa intermediária de valores a qual o ISA pode estar contido de modo a expressar a situação de salubridade de um determinado meio avaliado: 0,0 - 0,25 (Insalubre); 0,26 0,50 (Baixa Salubridade); 0,51 - 0,75 (Média Salubridade); 0,76 - 1,0 (Salubre).

Com o passar dos anos o método originalmente proposto para o ISA foi sofrendo alterações, de modo que ele pudesse ser aplicado em diferentes ambientes (Brustin, 2020). De uma forma geral, são realizadas inclusões ou retiradas de determinados subindicadores de maneira a se adaptar as particularidades das áreas urbanas ou rurais avaliadas. Portanto, os indicadores e suas ponderações podem variar de acordo com o critério adotado para cada estudo, podendo ser escolhido qual indicador terá mais foco, desde que a somatória final não ultrapasse o valor de 1,0 e assim, ter referência na escala da CONESAN. Deste modo, este sistema pode subsidiar atividades planejamento público e com este fim, a medição do ISA, tem se tornado de grande valia para os gestores públicos, pois ele é capaz, por exemplo, de prevenir doenças veiculadas pelo meio ambiente. No Brasil, há diversos estudos que propuseram a construção de seus indicadores para avaliar diferentes cenários (Albuquerque, 2013; Baggio, 2013; Bastos et al., 2014; Cabral, 2015; Santos et al., 2015). Neste contexto, este estudo teve como objetivo analisar o sistema de saneamento básico do campus universitário da Universidade Federal de Sergipe (cidade universitária Prof. José Aloísio de Campos), no município de São Cristóvão-SE, por meio da adaptação do Índice de Salubridade Ambiental levando em consideração suas particularidades sanitárias e estruturais.

A área de estudo em questão foi escolhida por se tratar de uma região que possui todas as características de um núcleo urbano para a avaliação do índice de salubridade ambiental, e também por possuir uma expressiva população de interesse social. Embora, possa ser classificada como uma cidade de pequeno porte $(<50.000$ habitantes), o campus contribui com diversas atividades que consomem água potável e que geram efluentes e resíduos sólidos significativamente, além de possuir infraestrutura de rede pluvial e ser suscetível a presença de diversos vetores.

\section{Metodologia}

\section{1 Área de estudo}

A cidade universitária em estudo está localizada na Avenida Marechal Rondon, s/n - Jardim Rosa Elze, São Cristóvão - SE, CEP: 49100-000 (coordenadas geográficas: 1055'31.50"S - latitude e 376'6.44"W - longitude) concentrada em um espaço com área total de $1.539 .310 \mathrm{~m}^{2}$, sendo $139.154,71 \mathrm{~m}^{2}$ de área construída. A Figura 1 apresenta uma foto de satélite da área de estudo, com detalhes das estruturas, edificações, vias e áreas verdes. 
Figura 1. Campus UFS São Cristóvão.

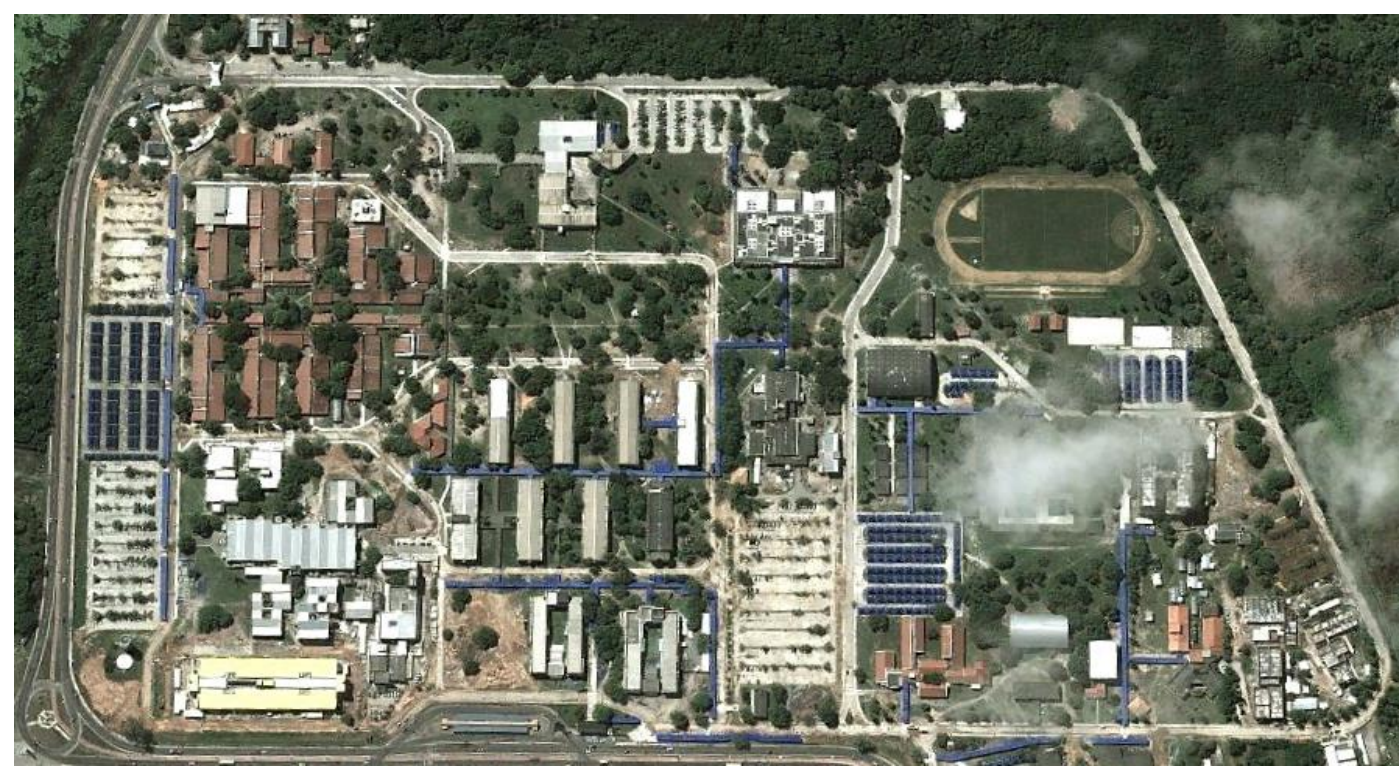

Fonte: Google EarthPro (2020).

É possível perceber pela Figura 1 que a área de estudo concentra expressivos pontos de edificações comuns a uma cidade universitária, tais como, biblioteca, departamentos de cursos, salas de aulas, restaurante, reitoria, prefeitura, estacionamentos, vias para transido de veículos e pedestres, além de áreas verdes. Os dados censitários mais recentes, contabilizam que o campus de São Cristóvão possui 23.220 alunos matriculados em ensino de graduação, 2.596 em ensino de pós-graduação e 406 em ensino fundamental e médio no semestre acadêmico de 2018 (cursos presenciais), além de 1.532 professores e 1.460 funcionários técnicos, totalizando uma população de 29.214 pessoas (UFS/COPAC, 2018).

\subsection{Desenho experimental}

Para a determinação do indicador específico ISA-UFS (adaptação do ISA original) levou-se em consideração uma metodologia de caráter exploratório de natureza quali-quantitativa de forma que os resultados foram expressos de forma descritivas, analíticos, com obtenção de dados e com interpretações em função das características observadas a respeito dos serviços de saneamento prestados à área de estudo. Assim, foram realizadas: i) Vistorias programadas em dias de chuvas para analisar a situação das vias em situações de alagamento e inundações. Inspeções para identificar a presença de bebedouros nas edificações e observar a frequência da limpeza urbana; ii) Estimar a frequência da falta de água potável e a presença de alguns vetores via percepção dos frequentadores; iii) Determinação analítica da qualidade de água potável para os parâmetros pH, turbidez e cloro residual de amostras de água coletadas em pontos representativos do campus: reitoria, edifícios destinados às aulas, departamentos de cursos (Engenharia Química, Engenharia Ambiental, Farmácia e Engenharia Civil); iv) Avaliação dos tipos e condições estruturais de vias superficiais, edificações existentes e a rede de abastecimento de água e de esgotamento sanitário. v) Avaliação da situação da coleta de resíduo sólido (comum e reciclável) junto à empresa responsável.

Em relação às determinações analíticas, foram utilizados equipamentos específicos, como: medidor de $\mathrm{pH}$ marca ITMPA 210; turbidímetro da marca LUTRON TU-2016; e medidor fotocolorímetro da HANNA modelo checker®hc hi701 para determinar o cloro residual. Para a avaliação da qualidade das amostras foi utilizado os valores limites padrão tabelados para turbidez, pH e cloro residual estabelecidos na Portaria de Consolidação nº 5/2017 do Ministério da Saúde. 


\subsection{Adaptações do indicador de salubridade ambiental}

A reformulação do ISA original para o ISA-UFS teve o intuito de expressar as condições de salubridade em funções dos subindicadores: Abastecimento de Água; Esgotamento Sanitário; Drenagem Urbana; Resíduo Sólido; e Controle de Vetores. Dessa forma os subindicadores de Recursos Hídricos e Socioeconômico foram excluídos.

Para a seleção dos subindicadores específicos foi levado em consideração o trabalho do ISA/JP (Levati, 2009), onde o subindicador de recurso hídricos foi substituído pelo subindicador de drenagem urbana, e para a determinação de como os subindicadores iriam ser calculados realizou-se uma adaptação do ISA/BG (Santos, 2016). Houve também reconsiderações em relação a ponderação dos subindicadores, sendo aplicado uma maior ponderação para o $\mathrm{I}_{\mathrm{AB}}$ e o $\mathrm{I}_{\mathrm{ES}}$, seguidos com segunda maior ponderação os $\mathrm{I}_{\mathrm{RS}}$ e $\mathrm{I}_{\mathrm{DU}}$, e por último o $\mathrm{I}_{\mathrm{CV}}$. Assim, o ISA-UFS foi construído para este estudo com a fórmula expressa pela Equação (2).

$$
I S A-U F S=0,25 I_{A B}+0,25 I_{E S}+0,20 I_{R S}+0,20 I_{D U}+0,10 I_{C V}
$$

A seguir são apresentados em detalhes os subindicadores específicos de segundo e terceiro níveis que compõem o ISA-UFS e suas considerações. Para a construção dos $I_{A B}, I_{E S}$ e $I_{R S}$ foram considerados como indicadores terciários a recomendação do ISA/BG (Tabela 1), sendo calculados através das Equações (3) a (5).

$$
\begin{aligned}
& I_{A B}=0,45 I_{Q A}+0,35 I_{T I A}+0,20 I_{F A} \\
& I_{E S}=0,50 I_{S C E}+0,30 I_{S T D S}+0,20 I_{D A S} \\
& I_{R S}=0,20 I_{L U}+0,30 I_{D L A}+0,20 I_{D L C}+0,10 I_{E C S}+0,20 I_{F C}
\end{aligned}
$$

\begin{tabular}{|c|c|c|c|c|}
\hline Variável & Sigla & Parâmetro & Critério & Pontuação \\
\hline \multirow{2}{*}{$\begin{array}{l}\text { Frequência do } \\
\text { Abastecimento }\end{array}$} & \multirow{2}{*}{$\mathrm{I}_{\mathrm{FA}}$} & \multirow{2}{*}{ Falta de água } & Frequente & $\begin{array}{l}\text { Mínimo de } 0 \text { quando } 100 \% \text { dos } \\
\text { entrevistados afirmarem frequente } \\
\text { falta d'agua. }\end{array}$ \\
\hline & & & Rara & $\begin{array}{c}\text { Máxima de } 1 \text { quando } 100 \% \text { dos } \\
\text { entrevistados afirmarem rara falta } \\
\text { d'agua. }\end{array}$ \\
\hline \multirow{2}{*}{$\begin{array}{c}\text { Tratamento Interno } \\
\text { da Água }\end{array}$} & \multirow[b]{2}{*}{$\mathrm{I}_{\mathrm{TIA}}$} & \multirow{2}{*}{$\begin{array}{l}\text { Bebedouro com filtro } \\
\text { acoplado }\end{array}$} & Realiza & $\begin{array}{l}\text { Máxima de } 1 \text { para } 100 \% \text { das } \\
\text { estruturas que possuem bebedouros. }\end{array}$ \\
\hline & & & Não realiza & $\begin{array}{c}\text { Mínima de } 0,5 \text { para } 100 \% \text { das } \\
\text { estruturas que não possuem nenhum } \\
\text { bebedouro. }\end{array}$ \\
\hline Qualidade da água & $\mathrm{I}_{\mathrm{QA}}$ & Turbidez & Há & $\begin{array}{l}\text { Mínima de } 0 \text { para água turva dos } \\
100 \% \text { das amostras coletadas e } \\
\text { segundo análise laboratorial (acima }\end{array}$ \\
\hline
\end{tabular}

Tabela 1. Método para o cálculo do Subindicador de Abastecimento de Água $\left(\mathrm{I}_{\mathrm{AB}}\right)$, de Esgoto Sanitário ( $\left.\mathrm{I}_{\mathrm{ES}}\right)$ de Resíduos Sólidos $\left(\mathrm{I}_{\mathrm{RS}}\right)$. 


\begin{tabular}{|c|c|c|c|c|}
\hline & & & & de 0,5 unT). \\
\hline & & & Não há & $\begin{array}{c}\text { Máxima de } 1 \text { para água límpida dos } \\
100 \% \text { das amostras coletadas e } \\
\text { segundo análise laboratorial (até } 0,5 \\
\text { unT). }\end{array}$ \\
\hline & & \multirow{2}{*}{$\mathrm{pH}$} & Há & $\begin{array}{c}\text { Mínima de } 0 \text { para resultado da } \\
\text { análise laboratorial para } \mathrm{pH} \text { abaixo } \\
\text { de } 6,5 \text { e acima de } 9,5 \text {. }\end{array}$ \\
\hline & & & Não há & $\begin{array}{l}\text { Máxima de } 1 \text { para resultado da } \\
\text { análise laboratorial entre } 6,5 \text { e 9,5. }\end{array}$ \\
\hline & & \multirow{2}{*}{ Cloro Residual } & Há & $\begin{array}{l}\text { Mínima de } 0 \text { para resultado da } \\
\text { análise laboratorial para cloro } \\
\text { residual menores que } 0,2 \mathrm{mg} / \mathrm{L} \text {. }\end{array}$ \\
\hline & & & Não há & $\begin{array}{l}\text { Máxima de } 1 \text { para resultado da } \\
\text { análise laboratorial para cloro } \\
\text { residual acima de } 0,2 \mathrm{mg} / \mathrm{L} .\end{array}$ \\
\hline \multirow{2}{*}{$\begin{array}{c}\text { Sistema de Coleta de } \\
\text { Esgoto }\end{array}$} & \multirow{2}{*}{$\mathrm{I}_{\mathrm{SCE}}$} & \multirow{2}{*}{ Sistema Coletivo } & Existência & $\begin{array}{l}\text { Máxima de } 1 \text { para existência de rede } \\
\text { coletora de esgoto em } \\
\text { funcionamento. }\end{array}$ \\
\hline & & & Inexistência & $\begin{array}{l}\text { Mínima de } 0 \text { para inexistência de } \\
\text { rede coletora de esgoto em } \\
\text { funcionamento. }\end{array}$ \\
\hline \multirow{2}{*}{$\begin{array}{c}\text { Sistema de } \\
\text { Tratamento de } \\
\text { Dejetos Sanitários }\end{array}$} & \multirow{2}{*}{$\mathrm{I}_{\mathrm{STDS}}$} & \multirow{2}{*}{$\begin{array}{l}\text { Sistema de } \\
\text { Tratamento Completo }\end{array}$} & $\begin{array}{l}\text { Estação de } \\
\text { tratamento }\end{array}$ & $\begin{array}{l}\text { Máxima de } 1 \text { para existência de uma } \\
\text { estação de tratamento. }\end{array}$ \\
\hline & & & Fossa séptica & $\begin{array}{c}\text { Mínima de } 0 \text { para existência de uma } \\
\text { fossa séptica. }\end{array}$ \\
\hline \multirow{3}{*}{$\begin{array}{l}\text { Disposição das Águas } \\
\text { Servidas }\end{array}$} & \multirow{3}{*}{$\mathrm{I}_{\mathrm{DAS}}$} & \multirow{3}{*}{$\begin{array}{l}\text { Disposição das águas } \\
\text { servidas }\end{array}$} & Adequada & $\begin{array}{c}\text { Máxima de } 1 \text { para a disposição em } \\
\text { rio ou córrego. }\end{array}$ \\
\hline & & & Intermediária & $\begin{array}{l}\text { Média de } 0,5 \text { para a disposição em } \\
\text { recipiente estanque. }\end{array}$ \\
\hline & & & Inadequada & $\begin{array}{l}\text { Mínima de } 0 \text { para a disposiç̧ão no } \\
\text { solo ao céu aberto }\end{array}$ \\
\hline \multirow{2}{*}{ Limpeza Urbana } & \multirow{2}{*}{$\mathrm{I}_{\mathrm{LU}}$} & \multirow{2}{*}{ Varrição } & Diária & $\begin{array}{l}\text { Máxima de } 1 \text { para observação de } \\
\text { limpeza diária. }\end{array}$ \\
\hline & & & Semanal & $\begin{array}{c}\text { Mínima de } 0 \text { para observação de } \\
\text { limpeza semanal. }\end{array}$ \\
\hline \multirow{3}{*}{$\begin{array}{c}\text { Destinação do Lixo } \\
\text { Após } \\
\text { Acondicionamento }\end{array}$} & \multirow{3}{*}{$\mathrm{I}_{\mathrm{DLA}}$} & \multirow{3}{*}{$\begin{array}{l}\text { Destinação pós } \\
\text { acondicionamento }\end{array}$} & $\begin{array}{c}\text { Coleta pelo } \\
\text { caminhão do lixo }\end{array}$ & $\begin{array}{l}\text { Máxima de } 1 \text { para coleta feita pelo } \\
\text { caminhão do lixo. }\end{array}$ \\
\hline & & & $\begin{array}{l}\text { Descarte a céu } \\
\text { aberto }\end{array}$ & $\begin{array}{c}\text { Mínima de } 0,2 \text { para descarte feito a } \\
\text { céu aberto. }\end{array}$ \\
\hline & & & $\begin{array}{l}\text { Queimado ou } \\
\text { enterrado }\end{array}$ & $\begin{array}{c}\text { Mínima de } 0,2 \text { para destinação por } \\
\text { queima ou soterramento. }\end{array}$ \\
\hline \multirow{3}{*}{$\begin{array}{l}\text { Destinação do Lixo } \\
\text { Pós Coleta }\end{array}$} & \multirow{3}{*}{$\mathrm{I}_{\mathrm{DLC}}$} & \multirow{3}{*}{ Destinação pós coleta } & $\begin{array}{c}\text { Descarte no } \\
\text { Aterro Sanitário }\end{array}$ & $\begin{array}{l}\text { Máxima de } 1 \text { para descarte do lixo } \\
\text { no aterro sanitário. }\end{array}$ \\
\hline & & & $\begin{array}{c}\text { Descarte no } \\
\text { Aterro Controlado }\end{array}$ & $\begin{array}{c}\text { Mínima de } 0,3 \text { para descarte do lixo } \\
\text { no aterro controlado. }\end{array}$ \\
\hline & & & $\begin{array}{l}\text { Descarte a céu } \\
\text { aberto }\end{array}$ & $\begin{array}{c}\text { Mínima de } 0 \text { para descarte do lixo a } \\
\text { céu aberto. }\end{array}$ \\
\hline
\end{tabular}


Research, Society and Development, v. 10, n. 1, e9110111515, 2021

(CC BY 4.0) | ISSN 2525-3409 | DOI: http://dx.doi.org/10.33448/rsd-v10i1.11515

\begin{tabular}{|c|c|c|c|c|}
\hline \multirow{2}{*}{$\begin{array}{l}\text { Existência de Coleta } \\
\text { Seletiva }\end{array}$} & \multirow{2}{*}{$\mathrm{I}_{\mathrm{ECS}}$} & \multirow{2}{*}{ Coleta Seletiva } & Há & $\begin{array}{l}\text { Máxima de } 1 \text { para existência da } \\
\text { coleta seletiva. }\end{array}$ \\
\hline & & & Não há & $\begin{array}{c}\text { Mínima de } 0 \text { para inexistência de } \\
\text { coleta seletiva. }\end{array}$ \\
\hline \multirow{3}{*}{$\begin{array}{l}\text { Frequência da Coleta } \\
\text { Convencional }\end{array}$} & \multirow{3}{*}{$\mathrm{I}_{\mathrm{FC}}$} & \multirow{3}{*}{ Frequência } & Diária & Máxima de 1 para coleta diária. \\
\hline & & & $\begin{array}{c}\text { Três ou quatro } \\
\text { vezes por semana }\end{array}$ & Média de 0,8 para coleta semanal. \\
\hline & & & Mensal & Mínima de 0 para coleta mensal. \\
\hline
\end{tabular}

Os parâmetros turbidez, $\mathrm{pH}$ e cloro residual foi orientado pelos valores máximos permitidos para a água potável para cada parâmetro descritos na Portaria de Consolidação do Ministério da Saúde nº 5/2017.

Fonte: Autores.

Para a elaboração do subindicador de drenagem urbana foi realizada uma adaptação a partir da junção do ISA/BG e

ISA/CR (Levati, 2009) (Tabela 2), sendo calculado através da Equação (6).

$$
I_{D U}=0,50 I_{C P A V}+0,25 I_{S P A V}+0,25 I_{A V}
$$

Tabela 2. Método para o cálculo do Subindicador de Drenagem Urbana ( $\left.\mathrm{I}_{\mathrm{DU}}\right)$.

\begin{tabular}{|c|c|c|c|c|}
\hline Variável & Sigla & Parâmetro & Critério & Pontuação \\
\hline \multirow{2}{*}{$\begin{array}{l}\text { Áreas de Drenagem } \\
\text { com Pavimentação }\end{array}$} & \multirow{2}{*}{$\mathrm{I}_{\mathrm{CPAV}}$} & \multirow{2}{*}{ Alagamentos } & Não há & $\begin{array}{l}\text { Máxima de } 1 \text { para a não ocorrência de } \\
\text { alagamentos nas áreas de drenagem } \\
\text { com pavimentação. }\end{array}$ \\
\hline & & & Há & $\begin{array}{l}\text { Mínima de } 0 \text { para a ocorrência de } \\
\text { alagamentos nas áreas de drenagem } \\
\text { com pavimentação. }\end{array}$ \\
\hline \multirow{2}{*}{$\begin{array}{l}\text { Áreas de Drenagem } \\
\text { sem Pavimentação }\end{array}$} & \multirow{2}{*}{$\mathrm{I}_{\mathrm{SPAV}}$} & \multirow{2}{*}{ Alagamentos } & Não há & $\begin{array}{c}\text { Máxima de } 1 \text { para a não ocorrência de } \\
\text { alagamentos nas áreas de drenagem sem } \\
\text { pavimentação. }\end{array}$ \\
\hline & & & Há & $\begin{array}{c}\text { Mínima de } 0 \text { para a ocorrência de } \\
\text { alagamentos nas áreas de drenagem sem } \\
\text { pavimentação. }\end{array}$ \\
\hline \multirow{2}{*}{ Áreas Verdes } & \multirow{2}{*}{$\mathrm{I}_{\mathrm{AV}}$} & \multirow{2}{*}{ Frequência } & Há & $\begin{array}{c}\text { Máxima de } 1 \text { para a existência de áreas } \\
\text { verdes. }\end{array}$ \\
\hline & & & Não há & $\begin{array}{c}\text { Mínima de } 0 \text { para a não existência de } \\
\text { áreas verdes. }\end{array}$ \\
\hline
\end{tabular}

Fonte: Autores.

O subindicador de controle de vetores não teve indicadores terciários, já que este só leva em consideração a presença (pontuação mínima de 0 para 100\% dos entrevistados) ou ausência (pontuação máxima de 1 para 100\% dos entrevistados) de mosquitos, moscas, baratas e ratos, quantificados por meio de questionário eletrônico dirigido aplicado junto à população acadêmica. A determinação do $\mathrm{I}_{\mathrm{CV}}$ foi obtida por meio da média aritmética simples dos valores. 


\section{Resultados e Discussão}

\subsection{Avaliação geral}

Após uma avaliação prévia da área de estudo foi verificada que o campus conta com um sistema de saneamento completo no que se refere ao abastecimento de água, esgotamento sanitário, coleta de lixo e drenagem pluvial, no entanto sem avaliar a qualidade dos serviços prestados. Assim, o abastecimento de água é feito pela concessionária pública de saneamento do estado (DESO), o campus possui uma unidade de tratamento de esgotos própria e operada por funcionários da UFS, a coleta de resíduo não reciclável e de material reciclável são realizadas por empresas distintas, e há também estruturas e elementos para a drenagem de águas de chuva. Alguns serviços podem não alcançar sua maior eficiência, como será apresentado posteriormente, porém suas estruturas ou serviços estão presentes.

\subsection{Abastecimento de água}

O sistema de abastecimento da área de estudo é de responsabilidade da concessionária pública do estado, a DESO, que fornece, através da rede de água potável municipal, toda a demanda hídrica necessária. No entanto, o campus armazena momentaneamente essa água recebida em um reservatório interno do tipo enterrado, o qual devido as condições de manutenção e limpeza pode comprometer a qualidade dessa água. Outros pontos que podem afetar as características da água são as tubulações, conexões e acessórios hídricos antigos não preservados ou de baixa qualidade que possam existir no sistema. Sabendo-se destas informações a metodologia foi aplicada e os valores determinados para os subindicadores específicos de terceiro e por consequência de segundo nível (Tabela 3).

Tabela 3. Valores obtidos para subindicadores de segundo e terceiro nível de abastecimento de água.

\begin{tabular}{c|c}
\hline Subindicador & Valor \\
\hline Frequência do Abastecimento ( $\left.\mathrm{I}_{\mathrm{FA}}\right)$ & 0,75 \\
\hline Tratamento Interno da Água ( $\left.\mathrm{I}_{\mathrm{TIA}}\right)$ & 1,00 \\
\hline Qualidade da Água ( $\left.\mathrm{I}_{\mathrm{QA}}\right)$ & 0,50 \\
\hline Abastecimento de Água $\left(\mathrm{I}_{\mathrm{AB}}\right)$ & 0,73 \\
\hline
\end{tabular}

Fonte: Autores.

No cálculo de subindicador $\mathrm{I}_{\mathrm{FA}}$, o seu valor foi obtido a partir das respostas da população do campus, que responderam a um questionário eletrônico dirigido, onde 75\% responderam haver a falta de água, contra 25\% que disseram não haver a falta de água no campus. Em relação ao subindicador $\mathrm{I}_{\text {TIA }}$, o seu valor foi obtido após vistorias, onde comprovou-se que em 100\% dos edifícios da área de estudo possuíam pelo menos um bebedouro em funcionamento equipado com filtro internos ou externo. Para o subindicador de qualidade da água foram realizadas determinações específicas para as amostras de água coletadas em diversos pontos aleatórios do campus e realizadas comparações com os limites máximos permitidos para a água potável descritos na Portaria de Consolidação do Ministério da Saúde nº 5/2017. Após determinação dos valores, para cada parâmetro, foram aplicadas as pontuações pertinentes e realizada a média ponderada simples de forma a obter o valor final do indicador $\mathrm{I}_{\mathrm{QA}}$ (Tabela 4). 
Tabela 4. Valores dos parâmetros das amostras de água e suas pontuações.

\begin{tabular}{c|c|c|c|c|c|c}
\hline Local & $\begin{array}{c}\text { Turbidez } \\
\left.(\mathbf{u n T})^{*}\right)\end{array}$ & Pontuação & $\mathbf{p H}$ & Pontuação & $\begin{array}{c}\text { Cloro residual } \\
(\mathbf{m g} / \mathbf{L})\end{array}$ & Pontuação \\
\hline DEC & 0,04 & 1,0 & 6,98 & 1,0 & 0,01 & 0,0 \\
\hline DFAL & 0,73 & 0,0 & 7,00 & 1,0 & 0,15 & 0,0 \\
\hline Reitoria & 0,89 & 0,0 & 7,10 & 1,0 & 0,00 & 0,0 \\
\hline DEAM & 0,01 & 1,0 & 7,17 & 1,0 & 0,12 & 0,0 \\
\hline LABAM & 0,72 & 0,0 & 6,67 & 1,0 & 0,00 & 0,0 \\
\hline DID IV & 0,22 & 1,0 & 6,64 & 1,0 & 1,0 & 0,0 \\
\hline $\begin{array}{c}\text { Média da } \\
\text { Pontuação }\end{array}$ & & 0,5 & & & & 0,0 \\
\hline
\end{tabular}

Média Geral $\left(I_{Q A}\right)=\mathbf{0 , 5 0}$

*unT = Unidade Nefelométrica de Turbidez

Fonte: Autores.

Assim, a partir dos valores dos subindicadores específicos aplicados na Equação 3, foi possível obter o valor do $\mathrm{I}_{\mathrm{AB}}$ como sendo igual a 0,73. Este resultado, direciona para um enquadramento de média salubridade. Como recomendações para melhoria desse subindicador propõe-se ações simples como, a limpeza periódica do reservatório de armazenamento de água potável do campus.

\subsection{Esgotamento sanitário}

A área de estudo possui desde 2015 em suas instalações uma estação de tratamento de efluentes que foi projetada para atender a todos os usuários do campus, estimada com uma vida útil de 20 anos. O sistema possui uma rede de coleta de 3.500 metros de tubulações, três estações elevatórias e a estação propriamente dita dos efluentes sanitários (UFS, 2016).

A ETE-UFS opera 24 horas por dia e 7 dias na semana, sendo composta por um sistema de gradeamento, caixa de areia, medidor de vazão (calha Parshall), digestor anaeróbico de fluxo ascendente (DAFA), reator de lodo ativado (valo de oxidação), leitos de secagem de lodo, unidade de desinfecção por cloração (tanque de contato), e reservatório de acúmulo. Após o tratamento a disposição final do efluente ocorre no corpo hídrico da região, o Rio Poxim.

Os resultados obtidos para o indicador IES são apresentados na Tabela 5. O valor do subindicador I uma vez que todo o campus possui rede coletora de esgotamento sanitário instalada e em funcionamento. No entanto, ainda que haja a rede de esgotamento, a universalização do tratamento não ocorre. Foi estimado que $94 \%$ das edificações do campus tenham a rede de esgoto conectas à ETE, as demais edificações são conectas à fossa séptica, onde posteriormente por meio de caminhões tanques os efluentes são succionados e encaminhados à ETE, e por isso aos subindicadores $\mathrm{I}_{\mathrm{STDS}}$ e $\mathrm{I}_{\mathrm{DAS}}$ foram atribuídos os valores de 0,94 . 
Research, Society and Development, v. 10, n. 1, e9110111515, 2021

(CC BY 4.0) | ISSN 2525-3409 | DOI: http://dx.doi.org/10.33448/rsd-v10i1.11515

Tabela 5. Valores obtidos para os subindicadores de segundo e terceiro nível de esgotamento sanitário.

\begin{tabular}{c|c}
\hline Subindicador & Valor \\
\hline Sistema de Coleta de Esgoto $\left(\mathrm{I}_{\mathrm{SCE}}\right)$ & 1,0 \\
\hline Sistema de tratamento de dejetos sanitários ( $\left.\mathrm{I}_{\mathrm{STDS}}\right)$ & 0,94 \\
\hline Disposição das águas servidas ( $\left.\mathrm{I}_{\mathrm{DAS}}\right)$ & 0,94 \\
\hline Esgotamento Sanitário a ( $\left.\mathrm{I}_{\mathrm{ES}}\right)$ & 0,97 \\
\hline
\end{tabular}

Fonte: Autores.

Assim, a partir dos valores dos subindicadores de terceiro nível encontrados, o valor do $\mathrm{I}_{\mathrm{ES}}$ foi determinado pela Equação 4 como sendo igual a 0,97 (Salubre), onde considera-se um ambiente de difícil proliferação de doenças associadas ao contato com o efluente gerado.

\subsection{Sistema de coleta de resíduos sólidos}

O serviço de limpeza e coleta de lixo comum da UFS é operado por contrato estabelecido via licitação pública com uma empresa privada, a qual é a responsável pela coleta e transporte até o aterro sanitário do estado de Sergipe, em Rosário do Catete. Pelo contrato vigente, a limpeza está fixada em um ano, podendo ser prorrogável por mais quatro, e contempla uma coleta periódica dos resíduos sólidos contido nos contêineres dispostos nas vias comuns do campus por meio de veículo compactador. Os gestores da universidade estimulam a separação de material reciclável disponibilizando lixeiras diferenciadas para recebimento de material não-reciclável e reciclável, sendo este último coletado e direcionado para a Cooperativa dos Agentes Autônomos de Reciclagem de Aracaju (CARE). Ambos os serviços são realizados periodicamente, a coleta de resíduos comum e reciclável ocorrem três e quatro vezes na semana, respectivamente. Não sendo observadas faltas dos serviços prestados pelas empresas. O valor do subindicador de resíduos sólidos obtido pode ser observado na Tabela 6.

Tabela 6. Valores obtidos para subindicadores de segundo e terceiro nível de resíduos sólidos.

\begin{tabular}{c|c}
\hline Subindicador & Valor \\
\hline Limpeza Urbana ( $\left.\mathrm{I}_{\mathrm{LU}}\right)$ & 0,0 \\
\hline Destinação do Lixo Após Acondicionamento ( $\left.\mathrm{I}_{\mathrm{DLA}}\right)$ & 1,0 \\
\hline Destinação do Lixo Pós Coleta ( $\left.\mathrm{I}_{\mathrm{DLC}}\right)$ & 1,0 \\
\hline Existência de Coleta Seletiva $\left(\mathrm{I}_{\mathrm{ECS}}\right)$ & 1,0 \\
\hline Frequência da Coleta Convencional $\left(\mathrm{I}_{\mathrm{FC}}\right)$ & 0,8 \\
\hline Resíduos Sólidos $\left(\mathrm{I}_{\mathrm{RS}}\right)$ & 0,76 \\
\hline
\end{tabular}

Fonte: Autores.

A limpeza urbana, que é realizada parcialmente entre uma empresa privada e servidores da universidade, recebeu um valor mínimo, pois a varrição das áreas externas não é realizada diariamente em todas as vias, como requer o parâmetro. Já os três subindicadores $\mathrm{I}_{\mathrm{DLA}}$, $\mathrm{I}_{\mathrm{DLC}}$ e $\mathrm{I}_{\mathrm{ECS}}$ receberam a nota máxima, uma vez que a destinação do lixo após acondicionamento é feita pelo veículo coletor, a destinação do lixo pós coleta é em aterro sanitário e não em um lixão ou em um aterro controlado e há a 
existência da coleta seletiva. Por fim, a frequência da coleta convencional não teve uma pontuação máxima por não ser realizada diariamente, e neste caso, foi considerado a possibilidade do surgimento de vetores devido ao tempo de acondicionamento do resíduo, e ademais, nem todos os coletores são do tipo estanque. Assim, o valor do $\mathrm{I}_{\mathrm{RS}}$ foi determinado utilizando a Equação 5, de forma a obter a pontuação 0,76 (ambiente Salubre). Este subindicador ainda pode ser melhorado com implementações simples do serviço de limpeza diária das vias.

\subsection{Drenagem urbana}

A área de estudo conta com sistemas de drenagem havendo sarjetas e desaguadouros, além de pavimento que facilitam o escoamento das águas pluviais para fora das vias, embora nem sempre exista em todas as vias. Infelizmente, situações de entupimento desses elementos foram identificados. No entanto, possui uma rede pluvial diferenciada da rede de esgoto, e a rede pluvial encaminha a água em direção a bacia hidrográfica local. Em relação as vias externas do campus, após inspeção visual, foi constatado que elas são todas pavimentadas, no entanto, variam quanto ao seu revestimento, ora com trechos com cobertura asfáltica ora sem essa cobertura, sendo construídas com pedras do tipo paralelepípedo, e algumas apresentando ondulações claras devido ao recapeamento.

Em relação a condição de drenagem, foi possível observar, após os dias de chuvas moderada a intensa, que o campus apresenta alguns pontos de alagamento, variando desde pequenas poças persistentes a grandes acúmulos de água. No entanto, não foram encontradas ocorrências de inundações. Fora das áreas construídas, foi identificada a presença de grandes áreas gramadas e arborizadas no campus, que é um fator de grande importância para a drenagem natural.

Como pode ser observado pela Tabela 7, o valor do $I_{D U}$ determinado pela Equação 6 foi de 0,25, considerado insalubre pois as pontuações atribuídas aos subindicadores $\mathrm{I}_{\mathrm{CPAV}} \mathrm{e} \mathrm{I}_{\mathrm{SPAV}}$ foram iguais a zero, ou seja, não pode ser considerada desprezível a retenção de água nas vias e, ademais, foi considerado que as áreas impactadas neste estudo são as de grande movimentação de pessoas.

Tabela 7. Valores obtidos para subindicadores de segundo e terceiro nível de drenagem urbana.

\begin{tabular}{c|c}
\hline Subindicador & Valor \\
\hline Áreas De Drenagem Com Pavimentação ( $\left.\mathrm{I}_{\mathrm{CPAV}}\right)$ & 0,0 \\
\hline Áreas De Drenagem Sem Pavimentação ( $\left.\mathrm{I}_{\mathrm{SPAV}}\right)$ & 0,0 \\
\hline Áreas Verdes $\left(\mathrm{I}_{\mathrm{AV}}\right)$ & 1,0 \\
\hline Drenagem Urbana $\left(\mathrm{I}_{\mathrm{DU}}\right)$ & 0,25 \\
\hline
\end{tabular}

Fonte: Autores.

Como recomendação de melhoria desse subindicador sugerem-se: obras de infraestrutura direcionadas para adequação do pavimento uniformizando-o em relação a manta asfáltica e obras de manutenção de forma a deixá-lo sem ondulações e com caimento correto para os pontos de recebimento de água pluvial.

\subsection{Controle de vetores}

Para atribuição dos valores do subindicador $\mathrm{I}_{\mathrm{CV}}$, aplicou-se um questionário eletrônico dirigido à população acadêmica 
do campus de modo a avaliar a presença de vetores conforme a percepção dos envolvidos, e os resultados podem ser observados na Tabela 8 .

Tabela 8. Valores obtidos em questionário eletrônico dirigido sobre a presença de vetores na UFS (resposta dada à pergunta: Você já viu ou não os seguintes vetores pelo menos uma vez no campus).

\begin{tabular}{|c|c|c|c|c|}
\hline Vetores & Respostas & Porcentagem & Pontuação & $\begin{array}{l}\text { Média } \\
\text { (ICV) }\end{array}$ \\
\hline \multirow{2}{*}{ Mosquito } & Sim & 99,5 & \multirow{2}{*}{0,0005} & \multirow{9}{*}{0,30} \\
\hline & Não & 0,05 & & \\
\hline \multirow{2}{*}{ Mosca } & Sim & 88,0 & \multirow{2}{*}{0,1200} & \\
\hline & Não & 12,0 & & \\
\hline \multirow{3}{*}{ Barata } & Sim & 64,1 & \multirow{3}{*}{0,3590} & \\
\hline & & & & \\
\hline & Não & 35,9 & & \\
\hline \multirow{2}{*}{ Rato } & Sim & 26,6 & \multirow{2}{*}{0,7340} & \\
\hline & Não & 73,4 & & \\
\hline
\end{tabular}

Fonte: Autores.

A partir da atribuição da pontuação dos subindicadores específicos, calculou-se a sua média, sendo este o valor do $\mathrm{I}_{\mathrm{CV}}$, o qual foi considerado como de um ambiente de Baixa Salubridade no que se refere ao controle de vetores, demostrando que o campus necessita de ações de combate a esses transmissores avaliados. Como recomendações para melhoria deste subindicador estão combates direto aos insetos, identificação e eliminação dos criadouros.

\subsection{Indicador de salubridade ambiental para o campus UFS São Cristóvão (ISA-UFS)}

Após a determinação dos resultados provenientes dos subindicadores individuais, que obtiveram resultados bem distintos em relação ao resultado de salubridade, indo desde Insalubre até Salubre, foi possível calcular com auxílio da Equação 2 o resultado final para o ISA-UFS (Tabela 9).

Tabela 9. Valores dos subindicadores e do indicador de salubridade ambiental.

\begin{tabular}{c|c}
\hline Subindicador & Valor \\
\hline Abastecimento de Água $\left(\mathrm{I}_{\mathrm{AB}}\right)$ & 0,73 (Média Salubridade) \\
\hline Esgotamento Sanitário a ( $\left.\mathrm{I}_{\mathrm{ES}}\right)$ & 0,97 (Salubre) \\
\hline Resíduos Sólidos ( $\left.\mathrm{I}_{\mathrm{RS}}\right)$ & 0,76 (Salubre) \\
\hline Drenagem Urbana ( $\left.\mathrm{I}_{\mathrm{DU}}\right)$ & 0,25 (Insalubre) \\
\hline Controle de Vetores ( $\left.\mathrm{I}_{\mathrm{CV}}\right)$ & 0,30 (Baixa Salubridade) \\
\hline Salubridade Ambiental (ISA) & 0,66 (Média Salubridade) \\
\hline
\end{tabular}

Fonte: Autores. 
O resultado final obtido para o ISA-UFS coloca a área de estudo em uma situação de Média Salubridade, no entanto, com forte potencial de melhoria, após realização de poucas intervenções se enquadrando na faixa considerada Salubre.

\section{Conclusão}

O presente estudo, após adaptação e implementação do indicador de salubridade, conseguiu avaliar as condições atuais dos serviços de saneamento ambiental e estrutural da cidade universitária Prof. José Aloísio de Campos. O resultado do ISA-UFS demonstrou que a área de estudo possui uma situação favorável à saúde humana. Foi possível também apontar recomendações para melhorias dos subindicadores avaliados. A melhor e a pior condição avaliada foram para os serviços de esgotamento sanitário e drenagem pluvial, respectivamente. É importante mencionar que, alguns problemas que afetam um determinado serviço são decorrentes de problemas de outros serviços, como por exemplo, os pontos de alagamentos podem ser ocasionados por conta da falta de varrição diária das áreas externas, fazendo com que as folhas ou alguns resíduos fiquem acumulados, causando o entupimento das sarjetas ou impedindo a fluidez das águas da chuva, assim como, podem servir para criadouros de mosquitos. Em relação aos trabalhos futuros, sugere-se que seja reaplicado esta mesma metodologia periodicamente, recomenda-se a cada quatro anos, de forma a verificar a pontuação do indicador ISA-UFS ao longo do tempo e valorar as ações tomadas para o saneamento dentro do campus.

\section{Referências}

Albuquerque, M. M. (2013). Indicador de Salubridade Ambiental (ISA) como instrumento de análise da salubridade do ambiente da comunidade de Saramém em Brejo Grande (SE). Dissertação (Mestrado) em Desenvolvimento e Meio Ambiente, Universidade Federal do Sergipe, São Cristóvão.

Almeida, M. A. P. (1999). Indicadores de Salubridade Ambiental em Favelas Urbanizadas: O Caso de Favelas em Áreas de Proteção Ambiental. Tese (Doutorado) em Engenharia de Construção Civil e Urbana da Escola Politécnica, Universidade de São Paulo, São Paulo.

Baggio, D. B. (2013). Aplicação do Indicador de Salubridade Ambiental (ISA) no município de Cocal do Sul - SC. Dissertação (monografia) em Engenharia Ambiental, Universidade do Extremo Sul Catarinense, Criciúma.

Bastos, A. L., Gama, R. S., Cavalcante, A. S. G., \& Gama, J. A. S. (2014). Adaptação e aplicação do Índice de Salubridade Ambiental (ISA) para o município de Marechal Deodoro/AL. In: Congresso Norte Nordeste de pesquisa e Inovação-Anais, São Luís.

Brustin, P., Tischner, A., Dias, L., Barbado, N., \& Reis, A. (2020). Aplicação do índice de salubridade ambiental (ISA) para diagnóstico de áreas urbanas: um estudo dos municípios de Maringá-PR e Sarandi-PR. Revista Gestão \& Sustentabilidade Ambiental, 9, $234-252$.

Cabral, A. C. (2015). Indicador de Salubridade Ambiental relacionado ao consumo de energia e água em municípios lindeiros e não lindeiros ao Lago de Itaipu da Bacia Hidrográfica do Paraná III. Dissertação (Mestrado) em Engenharia em Energia na Agricultura, Universidade Estadual do Oeste do Paraná, Cascavel.

Conselho Estadual de Saneamento (CONESAN). (1999). ISA-Indicador de Salubridade Ambiental - Manual Básico: Conesan.

Oliveira, G., Scazufca, P., \& Pires, R. C. (2020). Ranking do saneamento 2020. São Paulo: Instituto Trata Brasil; <http://www.tratabrasil.org.br/saneamentono-brasil>.

Lei Estadual N 7.750 , de 31 de março de 1992. Dispõe sobre a Política Estadual de Saneamento, e dá outras providências. Assembleia Legislativa do Estado de São Paulo. <http://www.al.sp.gov.br/repositorio/legislacao/lei/1992/lei-7750-31.03.1992.html>.

Levati, M. (2009). Aplicação do Indicador de Salubridade Ambiental (ISA) para Áreas Urbanas. Estudo de Caso: Município de Criciúma-SC. Dissertação (mestrado) em Engenharia Ambiental da Universidade do Extremo Sul Catarinense, Criciúma.

Santos, R. F., Cabral, A. C., Frigo, E. P., Bastos, R. K., Plácido, H. F., \& Pinto, L. P. (2015). Aplicação de Indicadores no município de Palotina - PR. Brazilian Journal of Biosystems Engineering, 9, 84-89.

Santos, F. F. S. (2016). Adaptação do Indicador de Salubridade Ambiental (ISA) para Análise do Saneamento Básico na Cidade de Brejo Grande/SE. Dissertação (mestrado) em Desenvolvimento e Meio Ambiente da Universidade Federal de Sergipe, São Cristóvão.

Silva, S. S. S. (2020). Proposta de Adaptação do Índice de Salubridade Ambiental (ISA/FNS) ao município de Florianópolis (SC) com aplicação da metodologia Delphi.

UFS/COPAC. (2018). Anuário estatístico da UFS: 2016-2018. São Cristóvão: UFS. 